\title{
Lewinella antarctica sp. nov., a marine bacterium isolated from Antarctic seawater
}

Correspondence

Jang-Cheon Cho

chojc@inha.ac.kr

\author{
Hyun-Myung Oh, Kiyoung Lee and Jang-Cheon Cho
}

Division of Biology and Ocean Sciences, Inha University, Incheon 402-751, Republic of Korea

\begin{abstract}
A marine bacterium, designated IMCC $3223^{\top}$, was isolated from Antarctic coastal seawater and subjected to a polyphasic taxonomic investigation. Cells of the strain were Gram-negative, short to elongated rods that were orange-coloured but negative for flexirubin-type pigments, obligately aerobic, chemoheterotrophic and devoid of gliding or flagellar motility. On the basis of 16S rRNA gene sequence comparisons, the strain was closely related to members of the genus Lewinella (86.3-93.1\%) of the family 'Saprospiraceae' in the phylum Bacteroidetes; the most closely related species was Lewinella lutea (93.1\% similarity to the type strain). The DNA G + C content of the strain was $50.3 \mathrm{~mol} \%$ and the major respiratory quinone was MK-7. The predominant cellular fatty acids were $\mathrm{C}_{16: 1} \omega 7 \mathrm{c} /$ iso- $\mathrm{C}_{15: 0} 2-\mathrm{OH}(39.4 \%)$, iso- $\mathrm{C}_{15: 0}(15.9 \%), \mathrm{C}_{17: 1} \omega 7 \mathrm{c}$ $(10.5 \%)$ and $\mathrm{C}_{15: 1} \omega 6 \mathrm{c}(8.9 \%)$. 16S rRNA gene sequence analyses and the phenotypic and chemotaxonomic tests allowed the differentiation of strain $\mathrm{IMCC}_{2} 23^{\top}$ from all recognized species of the genus Lewinella. Therefore, strain IMCC $3223^{\top}$ represents a novel species of the genus Lewinella, for which the name Lewinella antarctica sp. nov. is proposed. The type strain is IMCC $3223^{\top}\left(=\right.$ KCCM $42688^{\top}=$ NBRC $\left.103142^{\top}\right)$.
\end{abstract}

The genus Lewinella (Sly et al., 1998) belongs to the family 'Saprospiraceae' within the phylum Bacteroidetes and currently contains the six species Lewinella cohaerens, L. nigricans, L. persica, L. lutea, L. marina and L. agarilytica, which were isolated from marine sources. L. cohaerens, $L$. nigricans and L. persica, isolated from littoral sediment samples and originally assigned to the genus Herpetosiphon by Lewin (1970), were later transferred to the new genus Lewinella on the basis of data from 16S rRNA gene sequence analyses (Sly et al., 1998). L. agarilytica (Lee, 2007) and L. lutea (Khan et al., 2007) were isolated from shallow marine sediment samples, whilst L. marina (Khan et al., 2007) was isolated from a sea snail. The members of the genus Lewinella are generally characterized as being Gram-negative, aerobic, flexirubin-negative, chemoheterotrophic rods or filaments (up to $25 \mu \mathrm{m}$ long). In the present study, a Gram-negative, chemoheterotrophic, orange-coloured, non-gliding bacterium, designated strain IMCC $3233^{\mathrm{T}}$, was isolated from Antarctic seawater and was found to represent a novel species of the genus Lewinella.

A seawater sample was collected from the coast of King George Island, Weaver Peninsula, western Antarctica (62

The GenBank/EMBL/DDBJ accession number for the 16S rRNA gene sequence of strain IMCC3223 ${ }^{\top}$ is EF554367.

A transmission electron micrograph of cells of strain IMCC $3223^{\top}$ and details of the cellular fatty acid compositions of strain IMCC $3223^{\top}$ and type strains of species of the genus Lewinella are available as supplementary material with the online version of this paper. $\left.14^{\prime} \mathrm{S} 58^{\circ} 47^{\prime} \mathrm{W}\right)$. Strain IMCC $3223^{\mathrm{T}}$ was isolated using a standard dilution-plating method on an oligotrophic medium, R2A agar (Difco), diluted 1:10 (v/v) with aged seawater that had been kept at $8{ }^{\circ} \mathrm{C}$ for 2 months. After determination of the optimum growth temperature, cultures of IMCC $3223^{\mathrm{T}}$ were maintained routinely on marine agar 2216 (MA; Difco) at $20{ }^{\circ} \mathrm{C}$.

An almost-complete sequence of the 16S rRNA gene (1452 bp) was obtained for strain IMCC $3223^{\mathrm{T}}$ as described previously (Cho \& Giovannoni, 2003). Phylogenetic analyses, including multiple alignment of $16 \mathrm{~S}$ rRNA gene sequences, determination of sequence similarity and generation of phylogenetic trees, were performed using the ARB package (Ludwig et al., 2004) and PAUP* (Swofford, 2002) as described previously (Cho \& Giovannoni, 2006). Sequence comparisons in the ARB database and BLASTN hits from GenBank showed that strain IMCC $3223^{\mathrm{T}}$ was closely related to members of the genus Lewinella. This Antarctic isolate was most closely related to L. lutea NBRC $102634^{\mathrm{T}}$ (93.1\%) and shared 86.3-93.1\% 16S rRNA gene sequence similarity with respect to other members of the genus Lewinella. To clarify the phylogenetic position of the strain, 1296 unambiguously aligned nucleotide positions were used for the phylogenetic analyses. Phylogenetic trees were inferred using the maximum-likelihood (Felsenstein, 1981), maximum-parsimony (Fitch, 1971) and neighbour-joining (Saitou \& Nei, 1987) algorithms. The robustness of the topologies for the maximum-likelihood and neighbour-joining trees was evaluated by means of 
bootstrap analysis (Felsenstein, 1985) based on 100 and 1000 resamplings of the sequences, respectively. All of the phylogenetic trees generated in this study (Fig. 1) indicated that the Antarctic marine strain belonged to the genus Lewinella. Strain IMCC $3223^{\mathrm{T}}$ formed a coherent clade with L. lutea NBRC $102634^{\mathrm{T}}$ within the phylogenetically wellresolved Lewinella clade. This phylogenetic inference, together with the level of 16S rRNA gene sequence similarity (Wayne et al., 1987) between strain IMCC $3223^{\mathrm{T}}$ and the other Lewinella species $(<94 \%)$, suggested that the strain represented a novel species of the genus Lewinella.

The following characteristics were investigated using cultures grown on/in MA or marine broth 2216 at $20{ }^{\circ} \mathrm{C}$ according to methods described in a previous study (Choi et al., 2007) and standard methods (Smibert \& Krieg, 1994): cell morphology and size; colony morphology, size and colour; flagellar and gliding motilities; cellular and flexirubin-type pigments; ranges and optima of temperature, $\mathrm{pH}$ and salinity for growth; and oxidase and catalase activities. The MGC anaerobic system and AnaeroPACK Anaero (Mitsubishi Gas Chemical Company) were used to test for anaerobic growth. Cellular pigments were extracted with acetone/methanol $(1: 1, \mathrm{v} / \mathrm{v})$ and their absorption spectra were determined using a scanning UV/visible spectrophotometer (Optizen 2120UV; Mechasis). Basic biochemical tests and carbon-source-oxidation tests were performed using API 20NE and API ZYM strips (bioMérieux) and Biolog GN2 MicroPlates, according to the manufacturers' instructions, except that the strips were inoculated with bacterial suspensions in artificial seawater medium (Choo et al., 2007) and incubated at $20{ }^{\circ} \mathrm{C}$ for 3 days. Degradation of macromolecules was tested by incubating the Antarctic strain at $20{ }^{\circ} \mathrm{C}$ for 4 weeks on MA containing the following: starch $(0.2 \%, \mathrm{w} / \mathrm{v})$, casein $(10 \%$ skimmed milk, w/v), elastin $(0.5 \%$, w/v), chitin $(0.5 \%$, w/ v), agar $(1.5 \%, \mathrm{w} / \mathrm{v})$ and CM-cellulose $(0.2 \%, \mathrm{w} / \mathrm{v})$. Hydrolysis was indicated by the formation of clear zones around colonies either immediately or after flooding of the plate with the appropriate staining solution (Teather \& Wood, 1982). Ten different antimicrobial agents (listed in the species description) were tested using the diffusion plate method (Jorgensen et al., 1999) on MA incubated for 5 days at $20{ }^{\circ} \mathrm{C}$. The DNA G $+\mathrm{C}$ content was determined by means of HPLC (Mesbah et al., 1989). The quinone content was analysed, at the Korean Culture Center of Microorganisms (Seoul, Republic of Korea), using reversed-phase HPLC. Cellular fatty acid methyl esters were prepared from cultures grown on MA for 5 days at $20{ }^{\circ} \mathrm{C}$ and analysed, at the Korean Culture Center of Microorganisms, using the MIDI Microbial Identification System. For fatty acid analyses, strain IMCC $3223^{\mathrm{T}}, L$. cohaerens ATCC $23123^{\mathrm{T}}$, L. persica ATCC $23167^{\mathrm{T}}$ and $L$. nigricans ATCC $23147^{\mathrm{T}}$ were grown under the same culture conditions.

Phenotypic characteristics of strain IMCC $3223^{\mathrm{T}}$ are listed in Table 1 and in the species description. Cells of strain IMCC $3223^{\mathrm{T}}$ were Gram-negative, orange-coloured, obligately aerobic, chemoheterotrophic, non-motile, short to elongated long rods (see Supplementary Fig. S1, available in IJSEM Online). Strain IMCC $3223^{\mathrm{T}}$ exhibited a number of phenotypic similarities with respect to species of the genus Lewinella, including cell morphology, orangecoloured pigments, an $\mathrm{NaCl}$ requirement for growth, obligately aerobic growth, the presence of starch and gelatin hydrolysis, MK-7 as the major quinone and the absence of flexirubin-type pigments and gliding motility. These features of strain IMCC $3223^{\mathrm{T}}$ are typical of members of the genus Lewinella (Khan et al., 2007). However, several growth characteristics of IMCC $3223^{\mathrm{T}}$, such as its psychrotolerant nature, its ability to reduce nitrate and its macromolecule-degradation profile, clearly differentiated this strain from the type strains of Lewinella species (Table 1). The major fatty acids found in strain IMCC $3223^{\mathrm{T}}$, i.e. $\mathrm{C}_{16: 1} \omega 7 c /$ iso- $\mathrm{C}_{15: 0} \quad 2-\mathrm{OH} \quad(39.4 \%), \mathrm{C}_{15: 0} \quad(15.9 \%)$, $\mathrm{C}_{17: 1} \omega 7 c(10.5 \%), \mathrm{C}_{15: 1} \omega 7 c(8.9 \%)$ and 10-methyl $\mathrm{C}_{19: 1}$

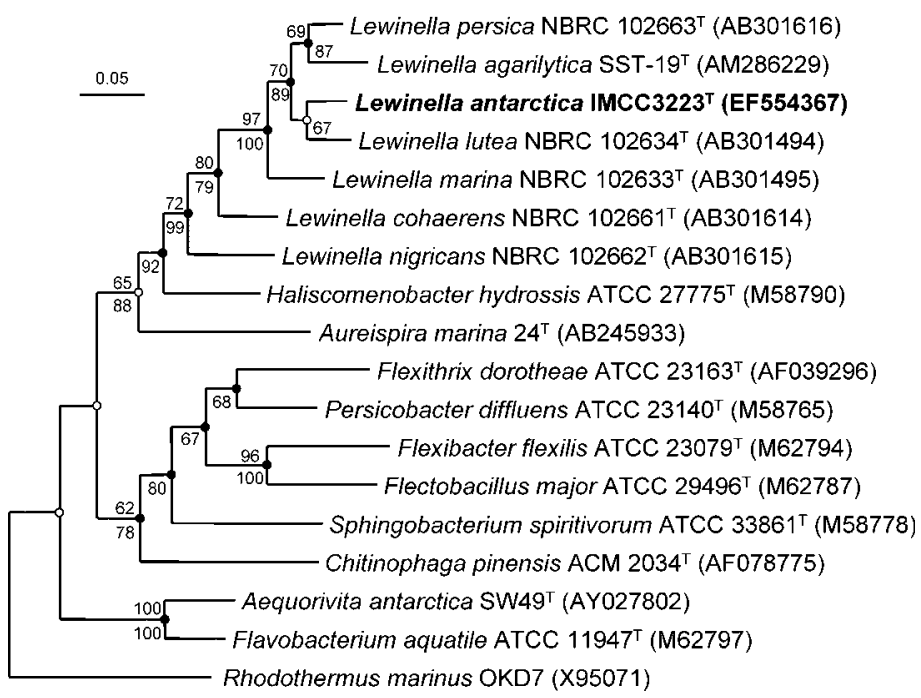

Fig. 1. Maximum-likelihood phylogenetic tree, based on 16S rRNA gene sequences, showing the relationships between strain IMCC $3223^{\top}$ and representatives of the phylum Bacteroidetes. Bootstrap proportions (>50\%) from both the maximum-likelihood analysis (above nodes) and neighbour-joining analysis (below nodes) are shown. Filled and open circles indicate nodes reproducibly recovered by all three treeing methods and by two treeing methods, respectively. The sequence of Rhodothermus marinus OKD7 was used as an outgroup. Bar, 0.05 substitutions per nucleotide position. 
Table 1. Characteristics that serve to differentiate strain IMCC $3223^{\top}$ from species of the genus Lewinella

Strains: 1, strain IMCC $3223^{\mathrm{T}}$; 2, L. cohaerens ATCC $23123^{\mathrm{T}}$; 3, L. nigricans ATCC $23147^{\mathrm{T}}$; 4, L. persica ATCC $23167^{\mathrm{T}}$; 5, L. agarilytica KCTC $12774^{\mathrm{T}}$; 6, L. lutea NBRC $102634^{\mathrm{T}} ; 7$, L. marina NBRC $102633^{\mathrm{T}}$. Data for reference strains were taken from Lee (2007) (L. agarilytica KCTC 12774 ${ }^{\mathrm{T}}$ ) and Khan et al. (2007) (other strains). All strains were negative for flexirubin-type pigments, indole production, acid production from glucose, arginine dihydrolase, urea hydrolysis and degradation of chitin. All strains were positive for degradation of starch and gelatin. +, Positive; -, negative; w, weak reaction.

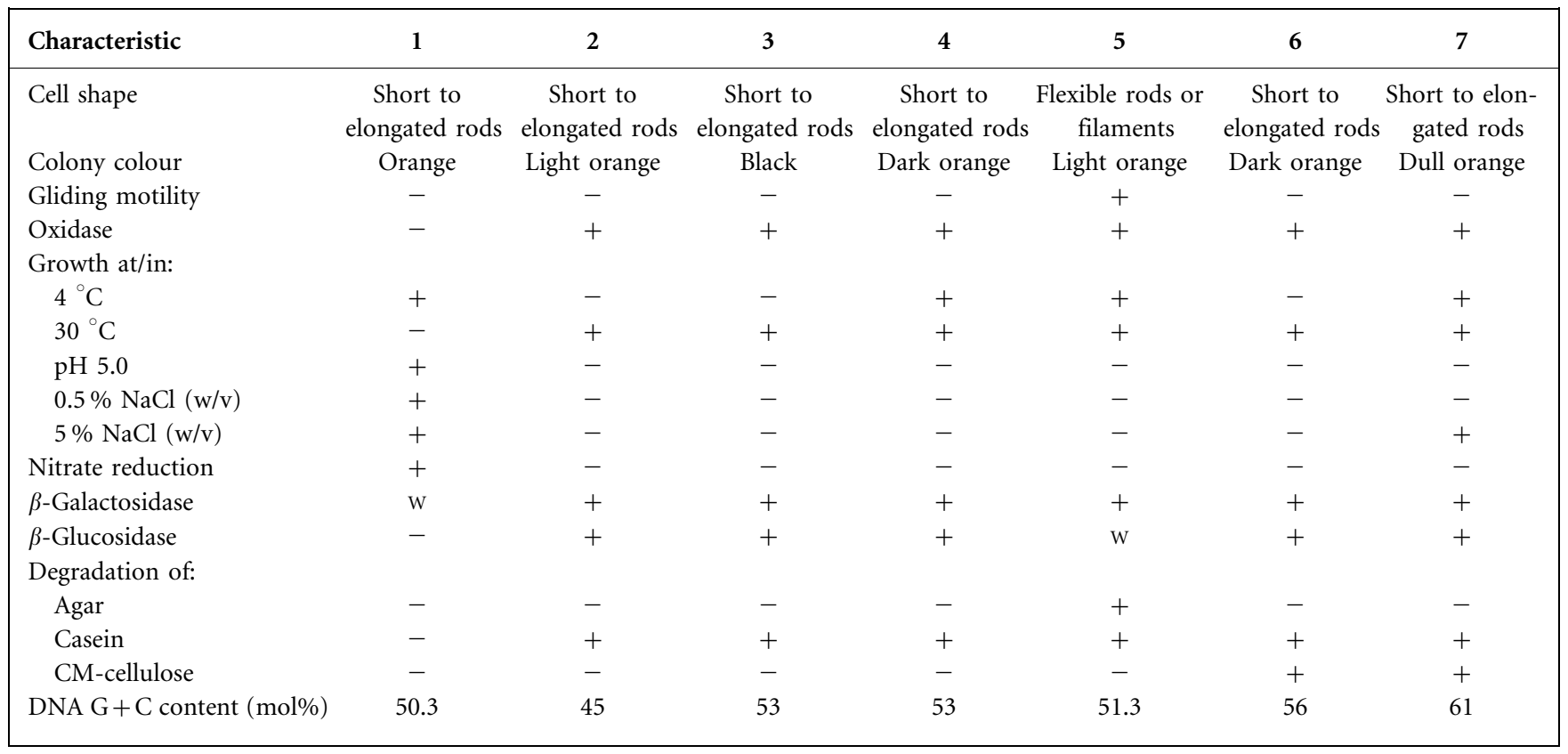

$(4.3 \%)$, also served to distinguish it from members of the genus Lewinella (Supplementary Table S1). The low level of $16 \mathrm{~S}$ rRNA gene sequence similarity $(<93.1 \%)$ with respect to species of the genus Lewinella, the distinct phylogenetic position (Fig. 1) and the presence of several differentiating phenotypic characteristics (Table 1) demonstrate that strain IMCC $3223^{\mathrm{T}}$ represents a novel species of the genus Lewinella (phylum Bacteroidetes), for which the name Lewinella antarctica sp. nov. is proposed.

\section{Description of Lewinella antarctica sp. nov.}

Lewinella antarctica (ant.arc'ti.ca. L. fem. adj. antarctica southern and, by extension, of the Antarctic, where the type strain was isolated).

Gram-negative, chemoheterotrophic, obligately aerobic, psychrotolerant, oxidase-negative and catalase-positive. Devoid of flagellar and gliding motility. Cells are short to elongated rods, $0.9-1.4 \mu \mathrm{m}$ wide and $2.4-21.2 \mu \mathrm{m}$ long. Colonies grown on MA for 5 days at $20{ }^{\circ} \mathrm{C}$ are circular, pulvinate, entire, butyrous, orange-coloured and $0.2-$ $0.6 \mathrm{~mm}$ in diameter. The temperature range for growth is $3-25{ }^{\circ} \mathrm{C}$, with optimum growth at $20{ }^{\circ} \mathrm{C}$. Growth occurs at $\mathrm{pH} 5.0-10.0$ and $0.5-5.0 \% \mathrm{NaCl}$, optimally at $\mathrm{pH} 6$ and $3.0 \% \mathrm{NaCl}$. Flexirubin-type pigments are not produced. Absorption spectra show peaks for cellular pigments at $472 \mathrm{~nm}$ (major peak) and $503 \mathrm{~nm}$. Starch and elastin are degraded, but agar, casein, CM-cellulose and chitin are not degraded. In API 20NE strips, nitrate reduction and hydrolysis of aesculin and gelatin are positive, $\beta$-galactosidase activity (substrate $p$-nitrophenyl $\beta$-D-galactopyranoside) is weakly positive and arginine dihydrolase, acid production from glucose, indole production and urea hydrolysis are negative. Positive results are obtained (in the API ZYM system) for acid phosphatase, alkaline phosphatase, leucine arylamidase, trypsin and valine arylamidase (weakly positive), but negative results are obtained for $\alpha$ fucosidase, $\alpha$-chymotrypsin, $\alpha$-galactosidase, $\alpha$-glucosidase, $\alpha$-mannosidase, $\beta$-galactosidase (substrate 2 -naphthyl $\beta$-Dgalactopyranoside), $\beta$-glucosidase, $\beta$-glucuronidase, cystine arylamidase, esterase (C4), esterase lipase (C8), lipase (C14), $N$-acetyl- $\beta$-glucosaminidase and naphthol-AS-BIphosphohydrolase. The following carbon substrates are oxidized (Biolog GN2 MicroPlates): $\alpha$-cyclodextrin, glycogen, cellobiose, i-erythritol, D-galactose, $\alpha$-D-glucose, $\alpha$ D-lactose, maltose, D-mannitol, melibiose, D-psicose, Lrhamnose, D-sorbitol, sucrose, trehalose, pyruvic acid methyl ester, acetic acid, D-galactonic acid lactone, Dgalacturonic acid, D-gluconic acid, $\alpha$-hydroxybutyric acid, $p$-hydroxyphenylacetic acid, $\alpha$-ketovaleric acid, succinic acid, succinamic acid, L-alaninamide, L-alanine, L-aspartic acid, L-glutamic acid, glycyl L-glutamic acid, L-serine, DLcarnitine, $\gamma$-aminobutyric acid, thymidine, phenylethylamine, 2-aminoethanol and $\alpha$-D-glucose 1-phosphate. None of the other carbon substrates in Biolog GN2 MicroPlates is oxidized. Susceptible to ampicillin $(10 \mu \mathrm{g})$, chlorampheni- 
col $(25 \mu \mathrm{g})$, erythromycin $(15 \mu \mathrm{g})$, rifampicin $(50 \mu \mathrm{g})$, streptomycin $(10 \mu \mathrm{g})$, tetracycline $(30 \mu \mathrm{g})$ and vancomycin $(30 \mu \mathrm{g})$, but resistant to gentamicin $(10 \mu \mathrm{g})$, kanamycin $(30 \mu \mathrm{g})$ and penicillin $\mathrm{G}(10 \mu \mathrm{g}$, weakly). In cultures grown on MA for 5 days at $20{ }^{\circ} \mathrm{C}$, the cellular fatty acids are $\mathrm{C}_{16: 1} \omega 7 c /$ iso- $\mathrm{C}_{15: 0} 2-\mathrm{OH}$, iso- $\mathrm{C}_{15: 0}, \mathrm{C}_{17: 1} \omega 7 c, \mathrm{C}_{15: 1} \omega 6 c$, 10-methyl $\mathrm{C}_{19: 0}$, iso- $\mathrm{C}_{15: 1}$, iso- $\mathrm{C}_{17: 0} 3-\mathrm{OH}$, iso- $\mathrm{C}_{16: 1}$, iso$\mathrm{C}_{17: 1} \omega 9 c, \mathrm{C}_{16: 0}, \mathrm{C}_{15: 0} \omega 8 c$ and iso- $\mathrm{C}_{15: 0} 3-\mathrm{OH}$. The major respiratory quinone is $\mathrm{MK}-7$. The DNA $\mathrm{G}+\mathrm{C}$ content of the type strain is $50.3 \mathrm{~mol} \%$.

The type strain, IMCC $3223^{\mathrm{T}}\left(=\mathrm{KCCM} 42688^{\mathrm{T}}=\mathrm{NBRC}\right.$ $103142^{\mathrm{T}}$ ), was isolated from surface seawater from Maxwell Bay, King George Island, western Antarctica.

\section{Acknowledgements}

We are grateful to Dr Soon-Gyu Hong and Dr Il-Chan Kim for providing Antarctic seawater samples. This research was supported by a research grant (PE07050) from the Korea Polar Research Institute (KOPRI) and by the 21C Frontier Program of Microbial Genomics and Applications from the MEST, Korea.

\section{References}

Cho, J.-C. \& Giovannoni, S. J. (2003). Parvularcula bermudensis gen. nov., sp. nov., a marine bacterium that forms a deep branch in the $\alpha$ Proteobacteria. Int J Syst Evol Microbiol 53, 1031-1036.

Cho, J.-C. \& Giovannoni, S. J. (2006). Pelagibaca bermudensis gen. nov., sp. nov., a novel marine bacterium within the Roseobacter clade in the order Rhodobacterales. Int J Syst Evol Microbiol 56, 855-859.

Choi, T.-H., Lee, H. K., Lee, K. \& Cho, J.-C. (2007). Ulvibacter antarcticus sp. nov., isolated from Antarctic coastal seawater. Int J Syst Evol Microbiol 57, 2922-2925.

Choo, Y.-J., Lee, K., Song, J. \& Cho, J.-C. (2007). Puniceicoccus vermicola gen. nov., sp. nov., a novel marine bacterium, and description of Puniceicoccaceae fam. nov., Puniceicoccales ord. nov., Opitutaceae fam. nov., Opitutales ord. nov. and Opitutae classis nov. in the phylum 'Verrucomicrobia'. Int J Syst Evol Microbiol 57, 532-537.

Felsenstein, J. (1981). Evolutionary trees from DNA sequences: a maximum likelihood approach. J Mol Evol 17, 368-376.

Felsenstein, J. (1985). Confidence limits on phylogenies: an approach using the bootstrap. Evolution 39, 783-791.

Fitch, W. M. (1971). Toward defining the course of evolution: minimum change for a specific tree topology. Syst Zool 20, 406-416.
Jorgensen, J. H., Turnidge, J. D. \& Washington, J. A. (1999). Antibacterial susceptibility tests: dilution and disk diffusion methods. In Manual of Clinical Microbiology, pp. 1526-1543. Edited by P. R. Murray, E. J. Baron, M. A. Pfaller, F. C. Tenover \& R. H. Yolken. Washington, DC: American Society for Microbiology.

Khan, S. T., Fukunaga, Y., Nakagawa, Y. \& Harayama, S. (2007). Emended descriptions of the genus Lewinella and of Lewinella cohaerens, Lewinella nigricans and Lewinella persica, and description of Lewinella lutea sp. nov. and Lewinella marina sp. nov. Int J Syst Evol Microbiol 57, 2946-2951.

Lee, S. D. (2007). Lewinella agarilytica sp. nov., a novel marine bacterium of the phylum Bacteroidetes, isolated from beach sediment. Int J Syst Evol Microbiol 57, 2814-2818.

Lewin, R. A. (1970). New Herpetosiphon species (Flexibacterales). Can J Microbiol 16, 517-520.

Ludwig, W., Strunk, O., Westram, R., Richter, L., Meier, H., Yadhukumar, Buchner, A., Lai, T., Steppi, S. \& other authors (2004). ARB: a software environment for sequence data. Nucleic Acids Res 32, 1363-1371.

Mesbah, M., Premachandran, U. \& Whitman, W. B. (1989). Precise measurement of the $\mathrm{G}+\mathrm{C}$ content of deoxyribonucleic acid by high-performance liquid chromatography. Int J Syst Bacteriol 39, 159-167.

Saitou, N. \& Nei, M. (1987). The neighbor-joining method: a new method for reconstructing phylogenetic trees. Mol Biol Evol 4, 406425.

Sly, L. I., Taghavi, M. \& Fegan, M. (1998). Phylogenetic heterogeneity within the genus Herpetosiphon: transfer of the marine species Herpetosiphon cohaerens, Herpetosiphon nigricans and Herpetosiphon persicus to the genus Lewinella gen. nov. in the FlexibacterBacteroides-Cytophaga phylum. Int J Syst Bacteriol 48, 731-737.

Smibert, R. M. \& Krieg, N. R. (1994). Phenotypic characterization. In Methods for General and Molecular Microbiology, pp. 611-654. Edited by P. Gerhardt, R. G. E. Murray, W. A. Wood \& N. R. Krieg. Washington, DC: American Society for Microbiology.

Swofford, D. (2002). PAUP* ${ }^{*}$ phylogenetic analysis using parsimony (and other methods), version 4. Sunderland, MA: Sinauer Associates.

Teather, R. M. \& Wood, P. J. (1982). Use of Congo red-polysaccharide interactions in enumeration and characterization of cellulolytic bacteria from the bovine rumen. Appl Environ Microbiol 43, 777-780.

Wayne, L. G., Brenner, D. J., Colwell, R. R., Grimont, P. A. D., Kandler, O., Krichevsky, M. I., Moore, L. H., Moore, W. E. C., Murray, R. G. E. \& other authors (1987). International Committee on Systematic Bacteriology. Report of the ad hoc committee on reconciliation of approaches to bacterial systematics. Int J Syst Bacteriol 37, 463-464. 